\title{
Pectin and complications after gastric surgery: normalisation of postprandial glucose and endocrine
} responses

\author{
D J A JENKINS, ${ }^{*}$ S R BLOOM, $\uparrow$ R H ALBUQUERQUE, A R LEEDS,$\ddagger$ \\ D L SARSON, G L METZ, AND K G M M ALBERTI $\dagger$
}

From the Department of the Regius Professor of Medicine, Radcliffe Infirmary, and University Laboratory of Physiology, Oxford; Gastroenterology Department, Central Middlesex Hospital, London; Royal Postgraduate Medical School, London; and Department of Clinical Biochemistry, Royal Victoria Infirmary, Newcastle upon Tyne

SUMmaRY Pectin has been shown to minimise the fall in blood glucose seen in patients who are troubled by hypoglycaemia attacks after gastric surgery. We therefore performed $50 \mathrm{~g}$ glucose tolerance tests with and without $14.5 \mathrm{~g}$ pectin on 11 post-gastric surgery patients. After pectin, the high postprandial levels of glucose, insulin, and enteroglucagon were significantly reduced as was the fall in blood glucose between 90 and 120 minutes. These effects of pectin may reflect slower uptake of glucose from the gastrointestinal tract and provide evidence to support the use of unabsorbable carbohydrate gelling agents in treating hypoglycaemia after gastric surgery.

As many as $5-10 \%$ of all patients who undergo gastric surgery are troubled with persistent symptoms such as early dumping, postprandial hypoglycaemia, or diarrhoea. ${ }^{1}$ These are thought to result from rapid emptying of hypertonic gastric contents into the duodenum.

Conventionally, such patients are advised to take frequent small dry meals, to avoid osmotically active foods-for example, sugar-and in severe cases may be prescribed anticholinergic drugs or given an antiperistaltic loop of small intestine at a subsequent operation. ${ }^{2}$ All these manoeuvres are aimed at reducing the rate of gastrointestinal transit.

Recently, viscous forms of carbohydrate (dietary fibre) have been shown to slow gastrointestinal transit and flatten the postprandial glucose and insulin response in healthy volunteers. ${ }^{3}$ Pectin, a fibre of this type, prevented symptoms of hypoglycaemia in patients after gastric surgery, ${ }^{4}$ delayed gastric emptying, and reduced the maximum change

\footnotetext{
*Address for correspendence and reprint requests: David J A Jenkins, University Laboratory of Physiology, Oxford OX1 3PT.

†DJAJ, SRB, and KGMMA are in receipt of grants from the British Diabetic Association.

¥ARL was in receipt of an MRC Training Award.

Received for publication 5 February 1980
}

in plasma volume after oral glucose. ${ }^{5}$ As these changes are likely to be associated with a modified endocrine response, we therefore looked at the effect of pectin on the oral glucose tolerance test and the associated release of three hormones.

\section{Methods}

Eleven patients (Table 1) were investigated after referral to the Gastroenterology Department at Central Middlesex Hospital for problems thought to be related to previous gastric surgery.

Table 1 gives details of the patients except the presenting symptoms, which are given in Table 2 . Symptoms are those recorded at the first and, in most instances, one other interview with the patient and represent the patient's description of his problem over the previous one to four weeks. They do not represent the means of a daily symptom chart and thus, for example, only an approximation to the nearest quarter of an hour can be given for the timing of first appearance of the symptoms after a meal. Also the frequency of attacks of diarrhoea varied greatly from day to day and only the usual range for an individual is given in the Table.

On two separated days, after overnight fasts, each patient took $50 \mathrm{~g}$ glucose in $400 \mathrm{ml}$ water to 
Table 1 Details of patients

\begin{tabular}{clllll}
\hline Patient & $\begin{array}{c}\text { Age } \\
(y r)\end{array}$ & Sex & $\begin{array}{c}\% \text { Desirable } \\
\text { weight }\end{array}$ & Operation & $\begin{array}{c}\text { Years since } \\
\text { operation }\end{array}$ \\
\hline 1 & 74 & F & 102 & V+P & 13 \\
2 & 59 & M & 92 & Polya & 10 \\
3 & 73 & M & 93 & Polya & 24 \\
4 & 59 & F & 99 & V+Bilroth I 22 \\
5 & 56 & M & 116 & Polya & 3 \\
6 & 65 & M & 127 & V+G-J & 8 \\
7 & 58 & M & 120 & V+P & 1 \\
8 & 53 & M & 106 & V+P & 6 \\
9 & 35 & M & 94 & V+G-J & 1 \\
10 & 34 & F & 110 & Polya & 10 \\
11 & 50 & M & 88 & Polya & 8 \\
Mean & 56 & & 104 & & $9 \cdot 6$ \\
\pm SEM & \pm 3.9 & & $\pm 3 \cdot 8$ & & $2 \cdot 3$ \\
\hline
\end{tabular}

V: vagotomy. P: pyloroplasty. G-J: gastrojejunostomy.

which, on one occasion, $14.5 \mathrm{~g}$ high methoxy pectin had been added. Symptoms were noted throughout the test and venous blood samples were taken at $0,15,30,45,60,90$, and 120 minutes through a butterfly needle kept patent with heparinised saline. Each sample was divided into three aliquots. Blood glucose was analysed by one of two glucose oxidase techniques. ${ }^{6} 7$ In the first four studies, this was by autoanalyser on whole blood, ${ }^{6}$ and in the remaining studies perchlorate precipitated samples were stored at $-20^{\circ} \mathrm{C}$ so that an individual's test and control specimens could be analysed? in the same run to minimise inter-batch variation. Serum insulin was measured using a standard double antibody technique. ${ }^{8}$ Plasma enteroglucagon ${ }^{9}$ and gastric inhibitory peptide (GIP) ${ }^{10}{ }^{11}$ were both estimated by radioimmunoassay. Pure porcine GIP was used for standards, iodination (lactoperoxidase), and for raising the anti-serum (titre 1/96000). The assays were set up in duplicate tubes containing $600 \mu \mathrm{l}$ of 0.05 molar barbitone buffer (pH 8.0) and
$200 \mu 1$ unknown plasma. After four day's incubation at $4^{\circ} \mathrm{C}$, antibody-bound hormone was separated by charcoal precipitation of free hormone. Changes of $3 \mathrm{pmol} / \mathrm{l}$ plasma could be detected with $95 \%$ confidence and less than $1 \%$ cross-reactivity was seen with pure glucagon, secretin, or vasoactive intestinal polypeptide. Chromatographic analysis showed two major molecular forms of GIP in plasma, the majority of which co-eluted with the pure porcine standard $\left(K_{a v} 0.87\right)$ and the other was present as a larger molecular form $\left(K_{a v} \mathbf{0} \cdot 3\right)$.

Enteroglucagon (glucagon-like immunoreactivity of intestinal origin) was measured with an antiserum (R59) directed to the $\mathrm{N}$-terminal region of pancreatic glucagon. This appeared to react equally with pancreatic glucagon and glucagon-like material from human intestinal extracts and thus measured total glucagon immunoreactivity. The antibody also reacted fully with pure glicentin ${ }^{12}$ estimated gravimetrically. Pancreatic glucagon was measured using a C-terminally directed antiserum (RCS5) at a dilution of $1 / 320000$, which gives zero readings with pancreatectomised patients. Total plasma glucagon-like immunoactivity was measured using antiserum R59 at a 1/1600 dilution. The assay conditions for both antisera were the same as those used for GIP. Using monoiodinated glucagon label (specific activity 1.9 megacurie/mol) changes of $1.5 \mathrm{pmol} / 1$ in plasma pancreatic glucagon and changes of $5 \mathrm{pmol} / \mathrm{l}$ total plasma glucagon-like immunoreactivity could be detected with $95 \%$ confidence. Plasma enteroglucagon was derived by subtracting plasma pancreatic glucagon, which was usually of much lower concentration, from the measured total plasma glucagon-like immunoreactivity. Chromatographic analysis showed en-

Table 2 Times, severity, and frequency of symptoms

\begin{tabular}{|c|c|c|c|c|c|c|c|c|}
\hline \multirow[t]{2}{*}{ Patient } & \multirow[t]{2}{*}{ Sweaty } & \multirow[t]{2}{*}{ Dizziness } & \multirow{2}{*}{$\begin{array}{l}\text { Blurred } \\
\text { vision }\end{array}$} & \multirow[t]{2}{*}{ Tired|faint } & \multicolumn{2}{|c|}{ Abdominal } & \multirow[t]{2}{*}{ Diarrhoea } & \multirow{2}{*}{$\begin{array}{l}\text { Frequency } \\
\text { (days/week) }\end{array}$} \\
\hline & & & & & Pain & Distension & & \\
\hline 1 & & pct & & pct & $\mathrm{pc} \dagger$ & pct & $\begin{array}{r}2-4 \dagger \\
(2-6)\end{array}$ & 4-6 \\
\hline $\begin{array}{l}2 \ddagger \\
3\end{array}$ & $2 *$ & 2* & & $2 *$ & $\begin{array}{l}\frac{1}{1-\frac{1}{2}} \dagger \\
\mathrm{pc} \dagger\end{array}$ & $\frac{1}{2}-\frac{1}{2} \dagger$ & & $\begin{array}{l}7 \\
5\end{array}$ \\
\hline 4 & $\frac{1}{2} \dagger$ & $\frac{1}{2}+$ & $\frac{1}{2} \dagger$ & & & & $\begin{array}{l}3-1+* \\
(1-2)\end{array}$ & $2-6$ \\
\hline $\begin{array}{l}5 \\
6\end{array}$ & $1+$ & & & & & $\frac{1}{1} \dagger$ & $\begin{array}{l}\text { pc† } \\
(1-2)\end{array}$ & $\begin{array}{l}<1 \\
2-6\end{array}$ \\
\hline $\begin{array}{l}7 \\
8\end{array}$ & & pct & & $\mathrm{pc} \dagger$ & pc $\dagger$ & pc* & $\begin{array}{l}\frac{1}{2}-\frac{3+}{2+} \\
(1-2)\end{array}$ & $\begin{array}{l}2-6 \\
2-6\end{array}$ \\
\hline $9 \ddagger$ & $\mathrm{pc}-2 \dagger$ & $\mathrm{pc}-2 \dagger$ & pc-2† & $\mathrm{pc}-2 \dagger$ & pc $\dagger$ & pc* & $\begin{array}{l}p c-3^{*} \\
(1-2)\end{array}$ & 7 \\
\hline $10 \ddagger$ & $\mathrm{pc}-2 \dagger$ & pc-2† & $\mathrm{pc}-2 \dagger$ & $\mathrm{pc}-2 \dagger$ & & & $\begin{array}{l}\frac{1}{2}-1+ \\
(3-6)\end{array}$ & 7 \\
\hline 11 & & & & & $3^{*}$ & $3 *$ & & $<1$ \\
\hline
\end{tabular}

Time after meals: pc, immediately after; or fractions of an hour, as in patient records. Severity: * mild to moderate; $\dagger$ severe. Numbers in parentheses represent episodes of loose motions/day. $¥$ Symptoms of sweating, etc. relieved by taking carbohydrate foods. 
teroglucagon to be present in plasma in both large and small molecular forms but only the larger form $\left(K_{a v} \mathbf{0 . 2 6}\right)$ rose after the meal stimulus. For all assays interassay variation was less than $15 \%$.

The results are expressed as means \pm SEM and the significance of the differences was calculated using Student's $t$ test for paired data.

The investigation was approved by the Brent Health District Ethical Committee.

\section{Results}

After taking the glucose with pectin, the mean blood glucose response was markedly flattened. The glucose with pectin values were significantly below those found after glucose alone at 15, 30, and 45 minutes (Fig. 1). The five patients whose 120 minute control value was below $3.5 \mathrm{mmol} / \mathrm{l}$ (mean $2.7 \pm 0.4$ $\mathrm{mmol} / \mathrm{l})$ showed a mean of $5.0 \pm 0.6 \mathrm{mmol} / \mathrm{l}$ after pectin, the lowest value being $3.7 \mathrm{mmol} / \mathrm{l}$. In addition, after pectin, there was an even greater percentage reduction in the endocrine response (Fig. 1). Insulin levels were significantly lower at 15,30 , and 45 minutes; enteroglucagon levels were

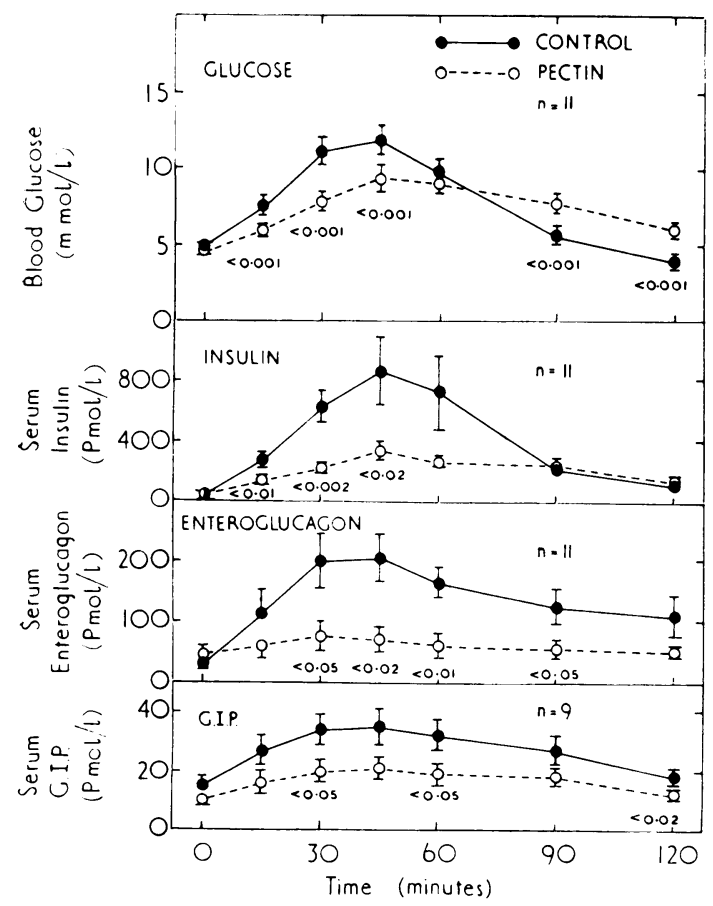

Fig. 1 Mean levels over two hours of blood glucose, serum insulin, enteroglucagon, and GIP in 11 post-gastric surgery patients who took $50 \mathrm{~g} G T T$ on two occasions, to one of which was added $14.5 \mathrm{~g}$ pectin.

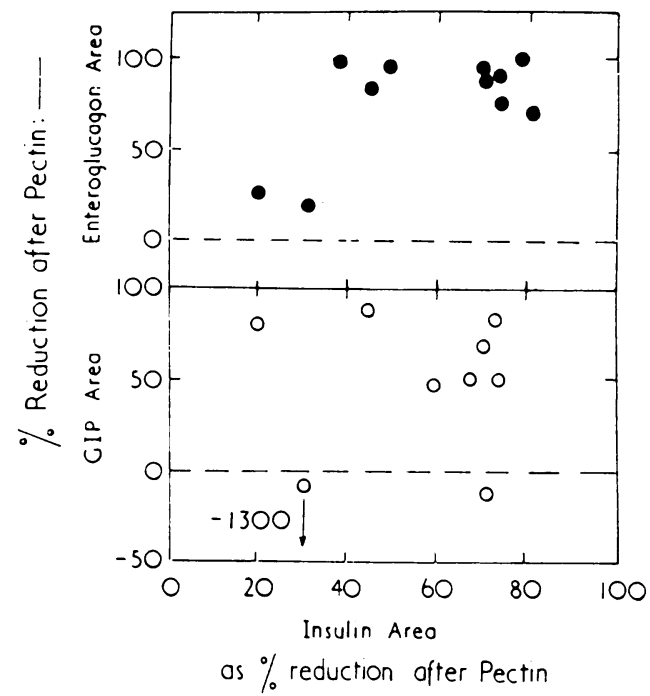

Fig. 2 Percentage reduction in GIP and enteroglucagon areas after pectin for individual patients plotted against their respective changes in insulin area (difference between test and control expressed as percentage of control).

significantly below control values at 30,45 , and 105 minutes; and GIP was significantly lower at 30 , 60 , and 120 minutes. Other differences did not reach significance (Fig. 1). Over the first hour, the reduction in the area calculated as the mean of the individual percentage difference between test and control pairs was $40 \%(\mathrm{P}<0.001)$ for glucose, $58 \%$ $(\mathbf{P}<0.001)$ for insulin, 76\% $(\mathbf{P}<0.001)$ for enteroglucagon, while for GIP there was a non-significant increase of $94 \%$. This GIP result was due to the inclusion of one patient (no. 4) who was unusual in showing virtually no rise in GIP on the control (area of $1 \mathrm{pmol} / \mathrm{h}$, mean for group, $16 \pm 3.5 \mathrm{pmol} / \mathrm{h}$ ) compared with $14 \mathrm{pmol} / \mathrm{h}$ rise on pectin (mean for group, $8 \pm 2 \cdot 1 \mathrm{pmol} / \mathrm{h}$ ). Calculated as the percentage change in area after pectin compared with the control this gave a percentage increase of 1300 . Such a figure was well over 2 SD from the mean and exclusion of this individual gave a mean reduction in the one hour GIP area for the remaining eight of $57^{\circ}$ o $(\mathrm{P}<0.002)$. There was a significant relationship only between the area changes in insulin and enteroglucagon ( $r=0.652, \mathrm{n}=11, \mathrm{P}<0.05)$ (Fig. 2 ). None of the endocrine area changes correlated significantly with each other or the change in the glucose area (Figs. 2 and 3).

The effect of pectin did not appear to be dependent on the severity of symptoms or the type of operation gerformed. When the five patients with polya gastrectomies were compared with five patients 


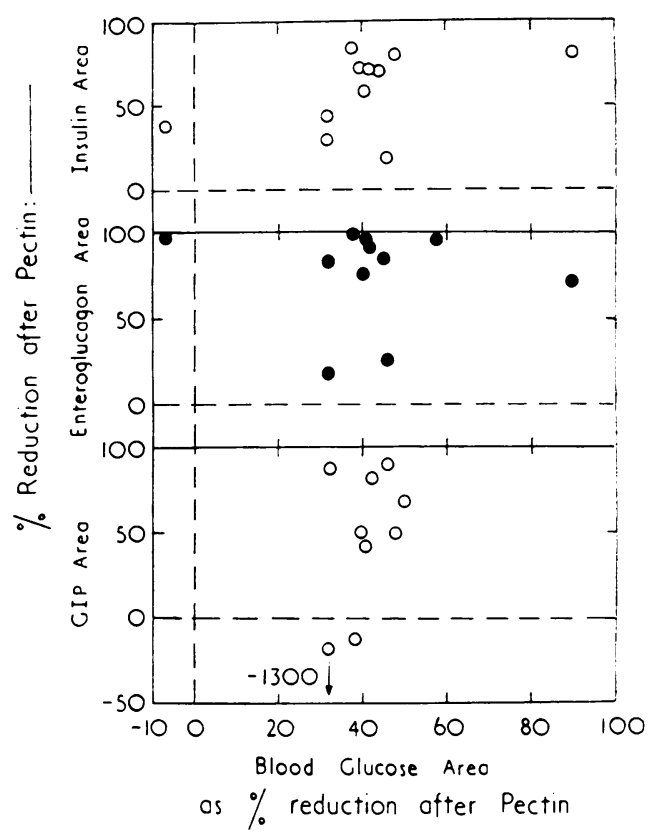

Fig. 3 Percentage reduction in insulin, GIP, and enteroglucagon areas for individual patients plotted against their respective changes in blood glucose area (difference between test and control expressed as percentage of control).

with vagotomy and a simple drainage procedure (pyloroplasty or gastroenterostomy) no significant difference was seen in response to pectin, although in general, with the exception of GIP, somewhat larger reductions in glucose and hormone areas were seen after vagotomy and drainage (Table 3 ).

During the control: two patients (nos. 2 and 10) felt dizziness and one (no. 10), in addition, experienced one of her typical attacks of trembling within 20 minutes of taking the glucose. These symptoms were not present when pectin was added. Three patients (nos. 1, 4, and 10) passed loose motions during the two hours after the control drink. Only one (no. 4) passed a motion after pectin and this was of a firm consistency.

\section{Discussion}

These results show that insulin, enteroglucagon, and, to a great extent, the blood glucose response to oral glucose can be normalised after gastric surgery by the addition of pectin to the drink.

In a study reported previously ${ }^{3}$ identical paired tests involving the use of pectin were performed on healthy volunteers whose age range (20-40 years) was younger than the patients reported here, but whose percentage ideal body weight was the same. Comparing the glucose and insulin responses of these two groups to $50 \mathrm{~g}$ glucose loads with and without pectin (Fig. 4) demonstrated abnormally high rises in both glucose and insulin in the patient group after the control glucose load. It also suggested that pectin was more effective in the patients than in the normal volunteers. It is not clear whether this is because a 'normal' response is difficult to 'improve' on or because there is a greater effect of viscosity in delaying gastric emptying or small intestinal absorption after gastric surgery. Similar quantities of the unabsorbable plant gums, guar and tragacanth, which are more viscous than pectin have been shown to reduce markedly both the glucose and insulin rises after glucose in normal subjects. $^{3}$ Although the glucose response in the patients after pectin was flattened, the levels from 45 minutes onwards were above the healthy control values (Fig. 4). This may be because of the older age of the patient group or of other factors associated with gastric surgery. The insulin response in the patient group, on the other hand, was reduced to a level which was almost identical with that of the normal volunteers after pectin (Fig. 4).

Previous studies of patients after gastric surgery have demonstrated abnormal glucose responses after oral ${ }^{13}{ }^{14}$ or intravenously injected glucose, ${ }^{15}$ but little data are available on the abnormal endocrine background. In a prospective study, insulin levels were shown to rise after vagotomy and pyloroplasty, but the difference was not significant. ${ }^{14}$ Other studies have demonstrated raised insulin and GIP levels. ${ }^{16}$ In our own studies, although the mean peak rise in GIP was markedly flattened after

Table 3 Comparison of effects of pectin in reducing glucose and hormone areas after oral glucose in patients with vagotomy and drainage or polya gastrectomy

\begin{tabular}{|c|c|c|c|c|c|}
\hline \multirow[t]{2}{*}{ Surgical procedure } & \multirow{2}{*}{$\begin{array}{l}\text { Number of } \\
\text { patients }\end{array}$} & \multicolumn{4}{|c|}{ Mean percentage reduction in area after pectin for: } \\
\hline & & Blood glucose & Serum insulin & Enteroglucagon & $G I P$ \\
\hline $\begin{array}{l}\text { Vagotomy and drainage } \\
\text { Polya gastrectomy }\end{array}$ & $\begin{array}{l}5 \\
5\end{array}$ & $\begin{array}{l}42 \pm 15 \\
40 \pm 2\end{array}$ & $\begin{array}{l}69 \pm 8 \\
54 \pm 10\end{array}$ & $\begin{array}{l}90 \pm 6 \\
75 \pm 13\end{array}$ & $\begin{array}{l}35 \pm 25 * \\
69 \pm 9\end{array}$ \\
\hline
\end{tabular}

* Mean of only three individuals.

NB The eleventh patient had a vagotomy and pyloroplasty which was later converted into Bilroth I gastrectomy and therefore does not fall directly into either group. 


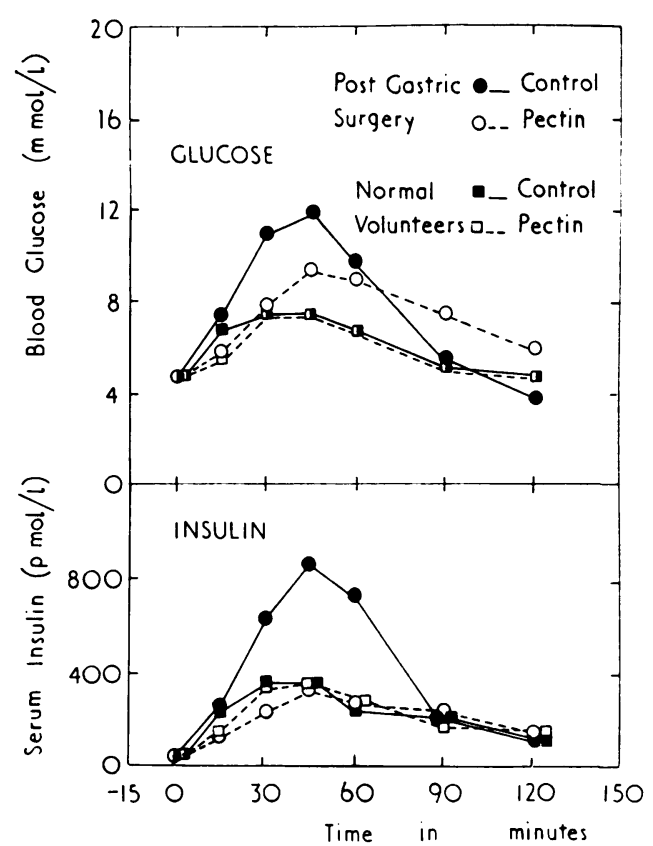

Fig. 4 Mean blood glucose and serum insulin responses after $50 \mathrm{~g}$ oral glucose tolerance tests with (test) or without (control) addition of $14.5 \mathrm{~g}$ pectin. Comparison of results on six healthy volunteers with those of the 11 post-gastric surgery patients.

pectin, the control rise was very similar to the value of $20-30 \mathrm{pmol} / \mathrm{l}$ found in control individuals after taking 50 g glucose. ${ }^{10}$

Nevertheless, we found greatly increased levels of enteroglucagon after glucose alone, which returned to normal after pectin administration. Using $100 \mathrm{~g}$ glucose loads, previous work on enteroglucagon levels after gastric surgery demonstrated mean peak rises of $58 \mathrm{pmol} / \mathrm{l}$ preoperatively, $214 \mathrm{pmol} / 1$ in postoperative patients with no symptoms and $564 \mathrm{pmol} / \mathrm{l}$ in patients with symptoms. Although our patients received only $50 \mathrm{~g}$ glucose, the mean peak rise for the whole group was $208 \pm 52$ $\mathrm{pmol} / \mathrm{l}$, while in the four patients with symptoms after glucose alone a mean peak rise of $374 \pm 92$ $\mathrm{pmol} / \mathrm{l}$ was seen. However, after pectin, the mean peak rise for the group was reduced to $56 \pm 18 \mathrm{pmol} / \mathrm{l}$, similar to that seen in preoperative patients. ${ }^{9}$ Neither here nor in the previously reported study9 was there a relationship between enteroglucagon levels and the type of surgery or the length of time postoperatively.

Unfortunately, as enteroglucagon has never been purified in significant quantities, there is no information on its pharmacology. In a single patient with an enteroglucagon-producing tumour, there was gross intestinal stasis and mucosal hypertrophy. ${ }^{17}$ Enteroglucagon levels have been found to be very raised in conditions of small intestinal mucosal damage-for example, coeliac disease ${ }^{18}$ or tropical sprue $^{19}$-after small intestinal resection, ${ }^{20}$ and after jejunoileal bypass procedures where, for example, the postprandial enteroglucagon rise may be raised by 16-fold. ${ }^{21}$ In all these conditions, nutrients pass further down the intestine than is normal.

Similarly, the results obtained in this study might also be a consequence of glucose passing further down the small intestine than normal. Rapid gastric emptying of hypertonic glucose solution into the small intestine would produce gastrointestinal hurry with glucose carried into the ileum and even lost to the colon as evidenced in a previous study by marked rises in breath hydrogen in five out of nine patients. ${ }^{4}$ This in turn would cause excessive enteroglucagon release, the hormonal peptide being found mostly in the distal small intestine and colon.

In this context, it is of interest that pectin has also been shown to reduce or eliminate the rise in breath hydrogen after glucose in gastric surgery patients, indicating a more complete absorption of glucose. ${ }^{4}$ This may help to explain the reduced enteroglucagon levels seen after pectin.

The action of pectin on GIP may result in part from its known ability to delay gastric emptying ${ }^{5}$ and thus the amount of glucose presented in unit time to the small intestine. Pectin has also been shown to reduce the change in plasma volume by $58 \%{ }^{5}$ indicating a reduction in the relative tonicity of the intraluminal contents and thus the effective concentration of glucose in contact with the small intestinal wall. For both these reasons, the stimulus to GIP release would be lessened. ${ }^{22}$

Conventionally, postprandial hypoglycaemia is viewed as a consequence of continuing high insulin levels at a time when there is little further glucose to be absorbed. The high insulin levels themselves are a direct response to the initial high blood glucose rises and the hormone changes are seen, therefore, as simply secondary to altered glucose handling.

In this study, such an interpretation can be questioned because of the lack of a significant relationship between changes in the areas under the one hour curve for glucose and insulin $(r=0.492$, $\mathrm{n}=11, \mathrm{P}>0 \cdot 1)$. It may be that the high insulin levels seen as precipitating hypoglycaemia after gastric surgery are also due in some measure to the abnormal gut endocrine response and are not solely related to raised postprandial glucose levels. Support for this lies in the significant relationship between the changes in insulin and enteroglucagon areas, 
though the excessive release of enteroglucagon in jejunoileal bypass patients, where insulin release is much reduced, would argue against this concept. On the other hand, if a normal GIP response is also required to enable enteroglucagon to show incretin-like activity, then jejunoileal bypass is not a good model. Here the GIP response to a meal is only $20 \%$ that seen in normal or obese individuals. ${ }^{21}$

Thus after pectin a combination of reduced effective glucose concentration, together with a more complete absorption of glucose higher in the small intestine, would remove a major part of the stimulus to both GIP22 and enteroglucagon release ${ }^{23}$ and perhaps other potential incretins. The reduction in stimulus to insulin release which would follow, with decreased risk of hypoglycaemia, would in turn be partly responsible for the reduction in symptoms seen after pectin.

We conclude that pectin, by normalising glucose and endocrine responses, makes the use of certain gel-forming polysaccharides relevant to the treatment of hypoglycaemia after gastric surgery.

We are grateful to Professor $\mathbf{J} \mathbf{L}$ Brown for the gift of pure porcine GIP.

\section{References}

${ }^{1}$ Smith FW, Jefferies GH. Late and persistent postgastrectomy problems. In: Sleisenger MH, Fordtran JS, eds. Gastrointestinal disease. Philadelphia: WB Saunders 1973: 822-28.

2Silen W. Peptic ulcer. In: Thorn GW, Adams RD, Braunwald E, et al., eds. Harrison's principles of internal medicine. New York: McGraw-Hill Book Co, 1977: 1494-510.

3Jenkins DJA, Wolever TMS, Leeds AR, et al. Dietary fibres, fibre analogues, and glucose tolerance: importance of viscosity. $\mathrm{Br} \mathrm{Med} J 1978 ; 1$ : 1392-4.

${ }^{4}$ Jenkins DJA, Gassull MA, Leeds AR, et al. Effect of dietary fibre on complications of gastric surgery: prevention of postprandial hypoglycaemia by pectin. Gastroenterology 1977; 73: 215-7.

${ }^{5}$ Leeds AR, Ralphs DN, Boulos P, et al. Pectin and gastric emptying in the dumping syndrome. Proc Nutr Soc 1978; 37: 23A (abstract).

${ }^{6}$ Trinder P. Determination of blood glucose using an oxidaseperoxidase system with a non-carcinogenic chromogen. J Clin Path 1969; 22: 158-61.

'Werner W, Rey HG, Wielinger H. Über die Eigen- schaften eines Chromogens für die Blutzuckerbestimmung nach der GOD/POD Methoden. Z Anal Chem 1970; 252: 224-7.

${ }^{8}$ Soeldner JS, Slone D. Critical variables in the radioimmunoassay of serum insulin using the double antibody techinque. Diabetes $1965 ; 14: 771-9$.

${ }^{9}$ Thomson JPS, Bloom SR. Plasma enteroglucagon and plasma volume change after gastric surgery. Clin Sci Mol Med 1976; 51: 177-83.

${ }^{10}$ Bloom SR. GIP in diabetes. Diabetologia 1975; 11: 334 (abstract).

${ }^{11}$ Sarson DL, Bryant MG. Bloom SR. A radioimmunoassay of gastric inhibitory peptide in human plasma. $J$ Endocrinol 1980 (In press).

${ }^{12}$ Sundby FS, Jacobsen $\mathrm{H}$, Moody AJ. Purification and characterisation of a protein from porcine gut with glucagon-like immunoreactivity. Hormone Metab Res 1976; 8: 366-71.

${ }^{13}$ Linquette M, Fourlinnie JC, Lagache G. Étude de la glycémie et l'insulinémie après vagotomie et pyloroplastie chez l'homme. Ann Endocr (Paris), 1969; 30 96-102.

${ }^{14}$ Hall WH, Sanders LL, Read RC. Effect of vagotomy and pyloroplasty: the oral glucose tolerance test. Gastroenterology 1973; 64: 217-22.

${ }^{15}$ Aagaard P, Deckert T, Fenger HJ. Serum insulin after intravenous administration of glucose before and after total vagotomy. Scand J Gastroenterol 1973; 8: 699-701.

${ }^{16}$ Thomford NR, Sirinek KR, Crockett SE, Mazzaferri EL, Cataland SE. Gastric inhibitory polypeptide: response to oral glucose after vagotomy and pyloroplasty. Arch Surg 1974; 109: 177-82.

${ }^{17}$ Bloom SR. An enteroglucagon tumour. Gut 1972; 13: 520-3.

${ }^{18}$ Besterman HS, Bloom SR, Sarson DL, et al. Gut hormone profile in coeliac disease. Lancet $1978 ; 1: 785-8$

${ }^{19}$ Besterman HS, Cook GC, Sarson DL, et al. Gut hormones in tropical malabsorption. Br Med J 1979; 2 1252-5.

${ }^{20}$ Bloom SR, Besterman HS, Adrian TE, et al. Gut hormone profile following resection of large and small bowel (abstract). Gastroenterology, 1979; 76: 1101.

${ }^{21}$ Besterman HS, Sarson DL, Blackburn AM, Cleary J, Pilkington TRE, Bloom SR. The gut hormone profile in morbid obesity and following jejuno-ileal bypass Scand J Gastroenterol 1978; 13 (Suppl. 49): 15.

${ }^{22}$ Thomas FB, Shook DF, O'Dorisio T, et al. Localization of gastric inhibitory polypeptide release by intestinal glucose perfusion in man. Gastroenterology, 1977; 72: $49-54$.

${ }^{23}$ Bloom SR, Polak J. Gut hormone overview. In: Bloom SR, ed. Gut hormones. Edinburgh: Churchill Livingstone 1978: 3-18. 